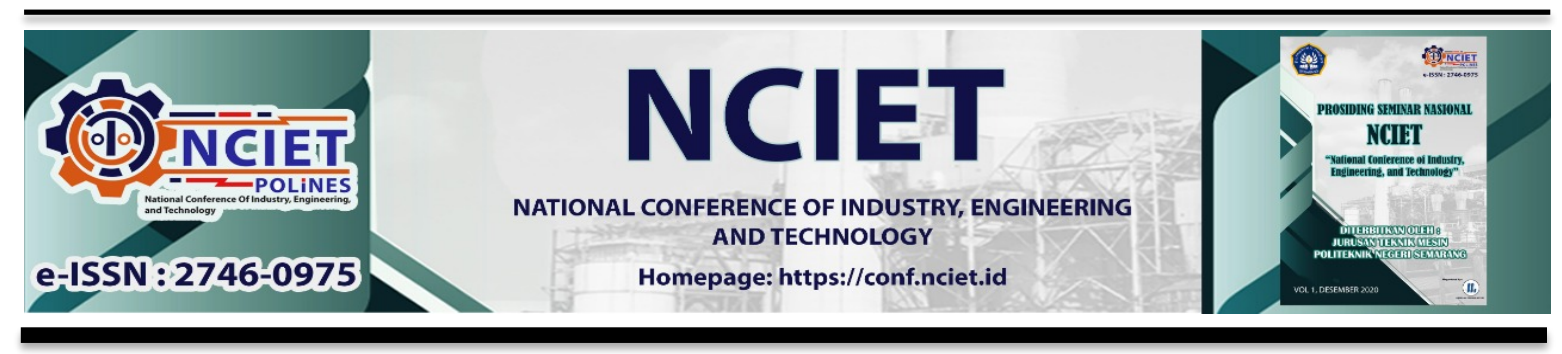

Prosiding Seminar Nasional NCIET Vol.1 (2020) B141-B149

$1^{\text {st }}$ National Conference of Industry, Engineering and Technology 2020,

Semarang, Indonesia.

\title{
ANALISA TAHANAN ISOLASI TRANSFORMATOR 3 DI PT.PLN (PERSERO) GARDU INDUK 150 KV PATI
}

\author{
Alinda Aisteti Yani“", Margono, Ken Hasto \\ Teknik Elektro, Universitas PGRI Semarang \\ Jl. Sidodadi TimurNo.24 Dr.Cipto, Karang Tempel, Semarang Timur, 50232 \\ *E-mail: upgris@upgris.ac.id
}

\begin{abstract}
Abstrak
Transformator daya adalah suatu peralatan tenaga listrik yang berfungsi untuk menyalurkan daya listrik tegangan tinggi ke tegangan rendah atau sebaliknya (mentransformasikan tegangan). Gangguan yang terjadi pada transformator dapat mengakibatkan terputusnya daya, oleh karena itu perawatan dan pengujiannya perlu dilakukan agar transformator dapat beroperasi sesuai masa pemakaiannya.Dalam operasi penyaluran tenaga listrik transformator dapat dikatakan sebagai jantung dari transmisi dan distribusi. Dalam kondisi ini suatu transformator diharapkan dapat beroperasi secara maksimal (kalau bisa terus menerus tanpa berhenti). Mengingat kerja keras dari suatu transformator seperti itu maka cara pemeliharaan juga dituntut sebaik mungkin. Oleh karena itu transformator harus dipelihara dengan menggunakan sistem dan peralatan yang tepat. Agar meminimalisasi kerusakan pada transformator. Tahanan isolasi digunakan untuk mengisolasi trafo agar tidak terjadi panas yang dapat merusak trafo itu sendiri. Pada tahanan isolasi Transformator ada beberapa cara untuk pengujian tahanan isolasi Transformator dikatakan masih bagus kinerjanya. Peratama, dengan menghitung Indeks Polarisasi (IP) sesuai dengan standar. Pengujian indek polarisasi yaitu membandingkan hasil tahanan setelah pengujian tegangan selama 10 menit dengan tahanan pada saat 1 menit pertama. Kedua, menghitung tangen delta yang bertujuan untuk mengetahui kualitas isolasi suatu peralatan listri dan untuk mengukur arus bocor kapasitif pada transformator Ketiga, melakukan pengujian minyak trafo, tujuannya yaitu untuk mengetauhi minyak masih baik atau tidak. Hasil perhitungan indeks polarisasi nilai yang didapat lebih dari 1,1-1,25 keadaan baik, dan apabila nilai dibawah 1,1-1,25 maka trafo perlu ada penangan. Perhitungan tangen delta menghitung tan delta agar mengetahui apakah tangen delta masih baik, jika nilai tan delta diatas $0,5 \%$ maka tangen delta jelek dan perlu diperiksa, jika nilai $0,5 \%$ kebawah maka tan delta hasilnya bagus. Terakhir pengujian minyak hanya dilakukan mengecheck keadaan minyak di suhu $30^{\circ} \mathrm{C}$ untuk trafo dan suhu $38^{\circ} \mathrm{C}$ untuk OLTC.
\end{abstract}

Kata Kunci: Tahanan Isolas; Indeks Polarisasi; Tangen Delta; Pengujian Minyak; Tegangan Tembus Minyak.

\section{PENDAHULUAN \\ Latar Belakang}

Fungsi utama sistem tenaga listrik adalah untuk melayani energi listrik kepada para konsumennya secara berkesinambungan. Beroperasinya transformator dengan baik adalah merupakan wujud usaha menjaga pasokan energi listrik dengan baik. Salah satunya dengan 
memperhatikan Tahanan Isolasi Transformator tersebut. Sebelum Transformator di operasikan maka akan dilakukan pengujian - pengujian transformator agar transformator tersebut bisa beroperasi dengan sebaik mungkin. Salah satu dari pengujian - pengujian Transformator adalah pengujian tahanan isolasi dan indeks polarisasi. Pengujian tahanan isolasi merupakan pengujian yang mengukur kebocoran arus melalui isolasi sedangkan indeks polarisasi merupakan petunjuk kekeringan dan kebersihan dari lilitan serta menentukan apakah peralatan aman untuk dioperasikan. Pengujian tahanan isolasi secara rutin dapat dilakukan dengan menggunakan Megger yang pembacaannya langsung dalam mega Ohm.

Dalam laporan ini penulis dapat melakukan pengujian tahanan isolasi dan menghitung nilai indeks polarisasi transformator untuk mendeteksi adanya kelemahan tahanan isolasi. Tahanan berubah-ubah karena pengaruh temperatur dan lamanya tegangan yang diterapkan pada lilitan tersebut, oleh karena itu factor - faktor tersebut harus dicatat pada waktu pengujian. nilai tahanan yang rendah dapat menunjukkan isolasi belitan peralatan tersebut dalam keadaan kotor atau basah.

\section{METODE PENILITIAN Pendekatan Penelitian}

Penelitian ini dilakukan agar audit yang menghitung indeks polarisasi, tangent delta, dan pengujian minyak.. Pendekatan yang digunakan penelitian ini adalah menggunakan pendekatan kuantitatif. Pendekatan kuantitatif sebagai penelitian yang menghasilkan data deskriptif berupa kata-kata tertulis atau lisan dari orang-orang dan perilaku yang dapat diamati. Dalam penelitian kuantitatif perlu menekankkan pentingnya kedekatan orang-orang dengan situasi penelitian, agar peneliti memperoleh pemahaman jelas tentang realitas dan kondisi kehidupan nyata.

\section{Waktu dan Tempat Penelitian}

Penelitian ini akan dilakukan di PT.PLN (Persero) Gardu Induk $150 \mathrm{KV}$ Pati . Penelitian dilakukan pada tanggal 24 Agustus 2020 s.d 15 September 2020.

\section{Tahap penelitian}

Tahapan penelitian yang dilakukan oleh penulis menggunakan metode sebagai berikut: a. Studi Literatur

Studi literatur dilakukan penulis untuk mencari referensi-referensi yang ada baik berupa buku maupun artikel ilmiah yang berhubungan dengan penyelesaian laporan ini. 
b. Perijinan dan pengambilan data penelitian

Dalam hal ini penulis melakukan perijinan kepada PT.PLN (Persero) Gardu Induk 150 KV Pati, untuk pengambilan data pengujian tahanan isolasi dan single line diagram kelistrikan transformator yang akan digunakan untuk pembuatan laporan.

c. Analisis Data

Penulis menganalisis data yang diperoleh dari proses pengambilan data untuk mengetahui perubahan kualitas kondisi isolasi pada transformator.

d. Pengujian

Pengujian dilakukan untuk mengetahui nilai yang akan digunakan untuk memberikan hasil yang lebih baik.

e. Penyelesaian laporan

Setelah data didapat dan dianalisis, laporan akan diselesaikan untuk pengambilan kesimpulan dan pemberian saran.

\section{HASIL DAN PEMBAHASAN}

\section{Spesifikasi Transformator}

Dalam melakukan pengukuran penulis harus mengetauhi spesifikasi Transformator yang akan diukur. Dibawah ini adalah spesifikasi Transformator yang akan dilakukan pengukuran.

Tabel 4. 1 Spesifikasi Trafo

\begin{tabular}{cc}
\hline Merk & CG Pauwels \\
\hline Yr. & 2014 \\
Manufactured & \\
VA Rating & $60 \mathrm{MVA}$ \\
kV Voltage & 150,20, \\
Serial & 3011130029 \\
Number & \\
Standar & IEC_60076 \\
Frequency & $50 \mathrm{~Hz}$ \\
Oil Volume & $21000 \mathrm{Kg}$ \\
Cooling & ONAN/ONAF- \\
& $60 / 100 \%$ \\
\hline
\end{tabular}




\begin{tabular}{ll}
\hline Type Of Oil & NYNAS \\
& NYTRO \\
& LIBRA \\
\hline
\end{tabular}

\section{Analisa Data dan Pengukuran Indeks Polarisasi}

Pengujian tahanan isolasi dimaksudkan untuk mengetahui kondisi isolasi antar lilitan maupun lilitan dengan ground. Metode pengujiannya dengan memberikan tegangan DC konstanlalu merepresentasikan kondisi isolasinya secara berkelanjutan dalam periode waktu yang lebih lama. Rasio perbandingan dari pembacaan uji 10 menit dengan uji 1 menit disebut Indeks Polarisasi (IP).

Tabel 4. 2 Data IP Tahun 2018 dan Tahun 2019 GI 150 Kv Pati

\begin{tabular}{|c|c|c|c|c|c|c|c|}
\hline \multirow[t]{2}{*}{ No. } & \multirow[t]{2}{*}{ Aktivitas } & \multicolumn{3}{|c|}{ Hasil Uji Th 2018} & \multicolumn{3}{|c|}{ Hasil Uji Th 2019} \\
\hline & & 1 Min & $10 \mathrm{Min}$ & IP & 1 Min & $10 \mathrm{Min}$ & IP \\
\hline 1 & Primary - Ground & 13,300 & 21,700 & 1,63 & 18,500 & 24,900 & 1,34 \\
\hline 2 & Sekundary - Ground & 14,100 & 22,100 & 1,56 & 16,600 & 23,400 & 1,40 \\
\hline 3 & Tertier - Ground & 14,000 & 21,400 & 1,52 & 88,000 & 174,000 & 1,97 \\
\hline 4 & Primary - Sekundary & 15,300 & 29,100 & 1,90 & 15,300 & 29,100 & 1,90 \\
\hline 5 & Primary - Tertier & 20,700 & 32,900 & 1,58 & 21,900 & 36,300 & 1,65 \\
\hline 6 & Sekundary -Tertier & 16,400 & 28,100 & 1,71 & 15,000 & 27,300 & 1,82 \\
\hline
\end{tabular}

Perhitungan Indeks Polarisasi yaitu sebagai berikut :

$$
I P=\frac{R_{10}}{R_{1}}
$$

Ketreangan :

IP $=$ IndeksiPolarisasi

$\mathrm{R}_{10}=$ Pengujian saat menit ke-10

$\mathrm{R}_{1}=$ Pengujian saat menit ke-1

Perhitungan indeks polarisasi primary-ground pada tabel 4.2 :

$$
\text { Pada Tahun 2018: } I P=\frac{21,700}{13,300}=1,63
$$

$$
\text { Pada Tahun 2019: } I P=\frac{24,900}{18,500}=1,34
$$

Dari tabel 4.2 Diatas maka diperoleh data pada Tahun 2018 yaitu Primary-Ground 1,63, Sekundary-Ground 1,56, Tertier-Ground 1,52, Primary-Skunder 1,90, Primary-Tertier 1,58, Sekundary-Tertier 1,71. Sedangkan pada tahun 2019 yaitu diperoleh Primary-Ground 1,34, Sekundary-Ground 1,40, Tertier-Ground 1,97, Primary-Skunder 1,90, Primary-Tertier 
1,65, Sekundary-Tertier 1,82. Dari data yang diperoleh diatas jika dibandingkan dengan standar pengujian IP yang diijinkan menurut ( Buku O\&M Trafo) masuk dalam kategori Baik yaitu nilainya berkisar antara 1,25 - 2,0. Ini menunjukkan bahwa nilai indeks polarisasi tahun 2018 dan tahun 2019 terbilang masih dalam keadaan baik.

Tabel 4. 3 Standar Pengujian IP yang diijinkan menurut ( Buku O\&M Trafo)

\begin{tabular}{ll}
\hline Hasil Pengujian & Keterangan \\
\hline$<\mathbf{1 , 0}$ & Berbahaya \\
$\mathbf{1 , 0}-\mathbf{1 , 1}$ & Jelek \\
$\mathbf{1 , 1}-\mathbf{1 , 2 5}$ & Dipertanyakan \\
& (pengujian \\
& tangen delta dan \\
& kadar minyak) \\
& Baik \\
$\mathbf{1 , 2 5}-\mathbf{2 , 0}$ & Sangat Baik \\
$\mathbf{> 2 , 0}$ & \\
\hline
\end{tabular}

\section{Analisa Data dan Pengukuran Perhitungan Tangen Delta}

Pengujian tan delta menunjukkan kekuatan isolasi, kehilangan daya dielektrik dan kelembaban berbagai macam bahan isolasi (Ravi, 2013). Isolasi yang baik akan bersifat kapasitif sempurna, dalam hal ini trafo dianggap sebagai kapasitor murni.

Tabel 4. 4 Data Tangen Delta Tahun 2019 GI 150kV Pati

\begin{tabular}{|c|c|c|c|c|c|}
\hline $\begin{array}{c}\text { Tegangan } \\
\text { (Kv) }\end{array}$ & $\begin{array}{l}\text { Arus } \\
(\mathrm{mA})\end{array}$ & $\begin{array}{l}\text { Daya } \\
\text { (Watt) }\end{array}$ & $\begin{array}{l}\text { TAN } \\
b(\%)\end{array}$ & $\begin{array}{l}\text { CAP } \\
(\mathbf{P F})\end{array}$ & $\begin{array}{l}\text { Corr } \\
\text { Fastor }\end{array}$ \\
\hline \multicolumn{6}{|c|}{ Inject HWPrimer } \\
\hline 10,00 & 27,221 & 0,3881 & 0,14 & $8.663,47$ & 0.810 \\
\hline 10,00 & 11,645 & 0,1941 & 0,17 & $3.078,67$ & 0.810 \\
\hline 10,000 & 38,821 & 0,5940 & 0,15 & 12.363 .25 & 0.810 \\
\hline \multicolumn{6}{|c|}{ Inject IIV : Silunder } \\
\hline 5.00 & 25,388 & 0,2020 & 0,16 & $16.183,34$ & 0.810 \\
\hline$\overline{5.00}$ & 1,666 & 0,0444 & 0,54 & 1.063 .90 & 0.810 \\
\hline$\overline{5,00}$ & 27,066 & 0,2533 & 0,19 & $17.245,39$ & 0.810 \\
\hline \multicolumn{6}{|c|}{ Inject HW:Tasier } \\
\hline 2,00 & 0,364 & 0,0057 & 0,78 & 581,25 & 0.810 \\
\hline 2,00 & 3,064 & 0,0329 & 0,39 & 4870,69 & 0.810 \\
\hline 2,000 & 3,426 & 0,0296 & 0,43 & $5,459,57$ & 0.810 \\
\hline
\end{tabular}

Keterangan pengukuran pada tabel di atas :

$\mathrm{CH}$ : Capacitance high 
CHL : Capacitance high low

CL : Capacitance low

$\mathrm{CT}$ : Capacitance tersier

CHT : Capacitance high tersier

CLT : Capacitance low tersier

Perhitungan tangen delta menggunakan rumus sebagai berikut :

$$
\operatorname{Tan} \delta=\frac{P}{V^{2} \omega C}
$$

Keterangan:

$\delta: \quad$ Delta

P : Daya (Watt)

$\mathrm{V}: \quad$ Tegangan (Volt)

C : $\quad$ Capasitance (F)

$\omega: \quad 2 \pi f$

Dari hasil pengujian pada tabel 4.5 maka perhitungan dapat dilakukan sebagai berikut: Perhitungan CHL :

Diket :

P : 0,3881 Watt

$\mathrm{V}: 10 \mathrm{kV}=10.000$ Volt

$\omega: 2 \pi \mathrm{f}$

$\mathrm{C}: 8.664,58 \mathrm{pF}=: 8.664,58 \times 10^{-12} \mathrm{~F}$

Tan $\delta=\frac{0,3881}{(10.000)^{2} \times 2 \times 3,14 \times 50 \times 8.664,58 \times 10^{-12}} \times 100 \%$

$=0,14 \%$

Tabel 4. 5 Standar Pengujian Tan Delta

\begin{tabular}{ll}
\hline Rating Power Fakt & \multicolumn{1}{c}{ Kondisi } \\
\hline$<\mathbf{0 , 5} \%$ & Baik \\
$<\mathbf{0 , 5} \% 0, \mathbf{7 \%}$ & Mengalami Penurunan \\
$\mathbf{0 , 7 \% - 1 , 0 \%}$ & Investigasi \\
$>\mathbf{1 , 0} \%$ & Buruk
\end{tabular}

Berdasarkan dari hasil data dan perhitungan manual yang sudah dilakukan kondisi belitan tan delta pada transformator menunjukkan bahwa Rating power faktor yakni sebesar 
$<0,5 \%-0,7 \%$. Ini menunjukkan bahwa transformator dalam kondisi mengalami penurunan. Untuk itu perlu dilakukan pertinjauan untuk melakukan pemeriksaan kadar air pada minyak isolasi.

\section{Analisa Data dan Pengujian Minyak}

Pengujian minyak yang dilakukan di gardu induk $150 \mathrm{kV}$ Pati melakukan test sebanyak 6 kali.

Tabel 4. 6 Data uji tegangan tembus minyak

\begin{tabular}{|c|c|c|c|c|c|c|}
\hline \multicolumn{7}{|c|}{ Hasl Pengujian kV } \\
Test l & Test 2 & Test 3 & Test 4 & Test5 & Test 6 & $\begin{array}{l}\text { Rata- } \\
\text { Rata }\end{array}$ \\
\hline $100,3 \mathrm{kV}$ & $92,1 \mathrm{kV}$ & $84,2 \mathrm{kV}$ & $94,5 \mathrm{kV}$ & $92,6 \mathrm{kV}$ & $93,5 \mathrm{kV}$ & $92,9 \mathrm{kV}$ \\
\hline
\end{tabular}

Tabel 4. 7 Standar Pengujian Tegangan Tembus Minyak

\begin{tabular}{|c|c|c|c|} 
Tegangan & Bagus & Cukup & Buruk \\
\hline $500 \mathrm{kV}$ & $>60 \mathrm{kV}$ & $50-60 \mathrm{kV}$ & $<50 \mathrm{kV}$ \\
\hline $150 \mathrm{kV}$ & $>50 \mathrm{kV}$ & $40-50 \mathrm{kV}$ & $<40 \mathrm{kV}$ \\
\hline $70 \mathrm{kV}$ & $>40 \mathrm{kV}$ & $30-40 \mathrm{kV}$ & $<30 \mathrm{kV}$ \\
\hline
\end{tabular}

Tabel 4. 8 Pengujian minyak OLTC ( On Load Tap Changer):

\begin{tabular}{|c|c|c|c|c|c|c|}
\hline Test l & Test 2 & Test 3 & Test 4 & Test 5 & Test 6 & $\begin{array}{c}\text { Rata- } \\
\text { Rata }\end{array}$ \\
\hline 31,9 & 26,7 & 32,3 & 24,8 & 24,3 & 29,1 & 28,2 \\
\hline
\end{tabular}

Tabel 4. 9 Standar Pengujian Minyak OLTC menurut IEC 60422

\begin{tabular}{c|c|c} 
Bagus & Cukup & Buruk \\
\hline$>40 \mathrm{kV}$ & $40 \mathrm{kV}$ & $<40 \mathrm{kV}$
\end{tabular}

Dari hasil data pada pengujian tegangan tembus minyak melalui pengujian BDV (Break Down Voltage). Hasil pengujian yang dilakukan selama 6 kali memiliki rata rata 92,9 kV . Dengan ini pengujian tegangan tembus masih dalam baik karena untuk transformator dengan tegangan $150 \mathrm{Kv}$ dalam kategori baik jika nilai rata-rata yaitu $>50 \mathrm{kV}$. Kemudian untuk Pengujian minyak OLTC juga dilakukan selama 6 kali dengan memiliki rata rata 28,2 kV yang menunjukan minyak OLTC buruk, untuk itu perlu adanya pergantian. Standar minyak dapat di katakan buruk jika $<40 \mathrm{Kv}$.Minyak yang masih bagus biasanya berwarna jernih sedangkan yang sudah buruk atau perlu pergantian berwarna coklat atau sudah keruh. 


\section{KESIMPULAN}

Dari hasil pengukuran dapat ditarik kesimpulan bahwa sebagai berikut :

1. Pada hasil pengujian diatas transformator 3 pada Gardu Induk $150 \mathrm{kV}$ Pati keadaan dari data yang didapat hasil yang baik, namun perlu dilakukan pengecekkan dan pembersihan pada minyak transformator karena didapatkan data pada Minyak OLTC (On Load Tap Changer) memiliki rata-rata $28,8 \mathrm{kV}$ yang menunjukkan minyak sudah dalam keadaan yang kurang baik dan harus dilakukan penggantian jika diperlukan.

2. Dari hasil pengukuran Indeks Polarisasi menunjukan bahwa nilai yang didapatkan masuk dalam kategori Baik yaitu nilainya berkisar antara 1,25 - 2,0. Ini menunjukkan bahwa nilai indeks polarisasi tahun 2018 dan tahun 2019 terbilang masih dalam keadaan baik.

3. Dari hasil pengukuran tan delta menunjukkan bahwa nilai kondisi belitan tan delta pada transformator yakni sebesar $<0,5 \%$ - 0,7\%. Ini menunjukkan bahwa transformator dalam kondisi mengalami penurunan. Untuk itu perlu dilakukan pertinjauan untuk melakukan pemeriksaan kadar air pada minyak isolasi.

4. Dari hasil data pada pengujian tegangan tembus minyak melalui pengujian BDV (Break Down Voltage). Hasil pengujian yang dilakukan selama 6 kali memiliki rata rata $92,9 \mathrm{kV}$. Dengan ini pengujian tegangan tembus masih dalam baik karena untuk transformator dengan tegangan $150 \mathrm{Kv}$ dalam kategori baik jika nilai rata-rata yaitu $>50 \mathrm{kV}$.

\section{DAFTAR PUSTAKA}

Anindyantoro, M. S. (2017). Analisa Tahanan Isolasi Pada Transformator Tenaga. 2.

Badaruddin, \& Firdianto, F. A. (2016). Analisa Minyak Transformator Pada Transformator Tiga Fasa. Jurnal Teknologi Elektro, Universitas Mercu Buana .

Chumaidy, A. (n.d.). Analisis Kegagalan Minyak Isolasi Pada Transformator Daya Berbasis Kandungan Gas Terlarut. Analisis Kegagalan Minyak Isolasi (Adib Chumaidy) , 43-44.

Erlina, \& Muhlas. (2016). Pengujian Kondisi Isolasi Main Transformator GTG 1.1. Jurnal Energi \& Kelistrikan Vol. 8 No. 2,

Fajarwati, M. (2018). Analisis Kondisi Hasil Pengujian TransformatorIII 150/20kV 16MVA GI Jajar Dalam Keadaan Padam. 4-7.

Fidianti, N. (2018). Analisis Tahanan Isolasi Peralatan.

Fitrizawati, Nurhadiyono, S., \& Ariawan, D. K. (2017). Analisis Penyebab Gangguan Pada Transformator Tenaga II -30 MVA 150 kV/20 kV Di Gardu Induk Mrica.

Garniwa, I., \& Fritz, J. S. (n.d.). Analisis Pengaruh Kenaikan Temperatur Dan Umur Minyak Transformator Terhadap Degradasi Tegangan Tembus Minyak Transformator. Nugrohor, D. (2010). Kegagalan Isolasi Minyak Trafo. Media Elektrika , 3, 2. 
P, S. I., Suharyanto, \& St, H. (2010). Pengujian Trafo Eksitasi Pusat Listrik Tenaga Air PB.Soedirman. Bidang Sistem Tenaga Listrik, 3 (4), 72.

Rezki, A., Wijaya, T. K., \& Irsyam, M. (2018). Analisa Pengujian Resistansi Tegangan Tembus Pada Oli Transformator 5.000 KVA DI PLTMG PANBIL. Sigma Teknika, 1.

Saepuloh, A., \& Andriyanto, Y. (2008). Pengujian Karakteristik Minyak. Buletin Pengelolaan Reaktor Nuklir. , 5 (2), 10.

Saputro, T. A. (2018). Analisis Hasil Pengujian Tahanan Isolasi Transformator Daya Berdasarkan HasilL Uji Indeks Polarisasi, TAangen Delta, RasioTegangan, BDV(Break Down Voltage). 12-14.

Siburian, J. (209). Karakteristik Transformator. JurnalL Teknologi Energi UDA , VIII, 2324.

Winanta, N. O., Amrita, A. A., \& Ariastina, W. G. (2019). Studi Tegangan Tembus Minyak Transformator. Jurnal SPEKTRUM , 6 (3), 16-17. 